\title{
Rationale, design and recruitment characteristics of a large, simple international trial of diabetes prevention: the DREAM trial
}

\author{
The DREAM Trial Investigators
}

\begin{abstract}
Aims/hypothesis. Diabetes is a rapidly rising independent risk factor for atherosclerosis and serious illness. This risk can be reduced by lifestyle changes and/or various drugs. Novel therapies to prevent diabetes, as well as new risk factors for diabetes, atherosclerosis and obesity require testing and identification.

Methods. People with impaired fasting glucose or impaired glucose tolerance were randomised to ramipril $(15 \mathrm{mg} /$ day $)$ or placebo and rosiglitazone $(8 \mathrm{mg} /$ day $)$ or placebo with a $2 \times 2$ factorial design. They are assessed semi-annually for the primary outcome (diabetes or death). Diabetes is diagnosed if two consecutive plasma glucose levels exceed diagnostic thresholds (i.e. fasting $\geq 7.0 \mathrm{mmol} / \mathrm{l}$ or $2-\mathrm{h} \geq 11.1 \mathrm{mmol} / \mathrm{l}$ ) within a 3 -month period. Assuming an annual primary outcome incidence of $5 \%$, there is more than $90 \%$ power to detect a $22 \%$ reduction. Approximately $20 \%$ of participants are having annual carotid ultrasounds to as-
\end{abstract}

sess the effects on atherosclerosis. Patients screened but not randomised are being followed prospectively to identify determinants of obesity, diabetes and related disorders.

Results. A total of 24,872 individuals in 21 countries were screened over 2 years and are eligible for followup. Of these, 5269 were randomised: $1835(35 \%)$ had isolated impaired glucose tolerance, 739 (14\%) had isolated impaired fasting glucose, and $2692(51 \%)$ had both disorders. Annual carotid ultrasounds are currently being performed in 1406 randomised individuals.

Conclusions/interpretation. The DREAM trial and related studies will determine if ramipril or rosiglitazone reduces the number of cases of diabetes and atherosclerosis, and will identify novel risk factors for diabetes.

Keywords Design - Diabetes prevention - Ramipril · Rosiglitazone $\cdot$ Trial
Received: 10 February 2004 / Accepted: 14 May 2004

Published online: 21 August 2004

C) Springer-Verlag 2004

Abbreviations: CV, cardiovascular · CVD, cardiovascular disease · DREAM, Diabetes Reduction Assessment with Ramipril and Rosiglitazone Medication · FPG, fasting plasma glucose · HOPE, Heart Outcomes Prevention Evaluation - STARR, Study of Atherosclerosis with Ramipril and Rosiglitazone - TMC, trial monitoring committee $\cdot \mathrm{TZD}$, thiazolidinedione

Corresponding author of the DREAM trial: H.C. Gerstein, c/o DREAM Project Office

Please address reprint requests to: DREAM Project Office, Population Health Research Institute, 237 Barton Street East, $2^{\text {nd }}$ Floor, Hamilton, Ontario L8L 2X2, Canada,

E-mail: dream@ccc.mcmaster.ca

The DREAM Trial Investigators as of December 2003 are listed at the end of the paper

\section{Introduction}

Risk of diabetes and its complications. At least $8 \%$ of people over the age of $20,12 \%$ of people aged between 40 and 74, and $19 \%$ of people aged 75 or over are estimated to have either established or undiagnosed diabetes mellitus, the majority of which is Type 2 diabetes [1]. Affected individuals have a high risk of blindness, renal failure, amputations, cardiovascular disease (CVD) and other problems, which together account for direct and indirect annual healthcare expenditures that exceeded $\$ 130$ billion dollars in 2002 in the United States alone [2]. Moreover, recent findings have shown that the risk of someone being affected by at least some of these complications, particularly cardiovascular (CV) diseases, is elevated at glucose levels well below the diabetes cut-off [3, 4]. This suggests 
that preventing the increase of glucose concentrations from levels that correspond with IGT or IFG to diabetic levels may reduce or eliminate these sequelae.

Several clinical trials have now shown that the incidence of Type 2 diabetes can be reduced in people with high risk by interventions that are typically used to reduce glucose levels in Type 2 diabetes patients. These include modest lifestyle changes, targeting a weight loss of approximately 5\% of body weight as well as 30 minutes of physical activity per day [5, 6]; metformin [5]; and acarbose [7]. However, because of the high and rising prevalence of Type 2 diabetes, and because the underlying cause is heterogeneous and poorly understood, different approaches to prevention need to be tested in a variety of high-risk populations. Of particular interest are interventions that have already been shown to reduce $\mathrm{CV}$ disease, atherosclerosis and renal disease. Moreover, novel determinants of IFG, IGT, diabetes and obesity need to be identified both to deepen insight into the pathogenesis of diabetes and to identify new preventive interventions.

ACE inhibitors may reduce the number of new cases of diabetes. It has been proven that ACE inhibitors reduce morbidity and mortality in a broad range of conditions $[8,9,10,11,12,13]$. In the Heart Outcomes Prevention Evaluation (HOPE) trial, the ACE inhibitor ramipril was found to reduce the risk of CV disease in a broad range of diabetic and non-diabetic individuals [8, 14]. It also reduced the risk of clinical proteinuria and modestly reduced the glycated haemoglobin level in people with diabetes [14]. The possibility that ramipril prevents the development of diabetes was explored using data from the 5720 nondiabetic individuals who were enrolled in the HOPE study [15]. During 4.5 years of follow-up, individuals allocated to ramipril were $34 \%$ less likely to report a new diagnosis of diabetes than those allocated to placebo (95\% CI: $15-49 ; p<0.001)$. These findings were robust; moreover, they were consistent with the change in glucose levels observed in a subset of nondiabetic people participating in a substudy of the HOPE trial. In the first 2 years the fasting plasma glucose increased by $0.41 \mathrm{mmol} / \mathrm{l}$ on placebo and by $0.25 \mathrm{mmol} / \mathrm{l}$ on ramipril $(p=0.028)$ [16].

The possibility that ACE inhibitors reduce the number of new cases of diabetes is also supported by data from the following: (i) the Captopril Primary Prevention Program [17], in which captopril-treated hypertensive individuals had a 14\% lower risk of developing diabetes over 6 years than people treated with a beta blocker or with thiazide; (ii) the Antihypertensive and Lipid Lowering Treatment to Prevent Heart Attack Trial [18], in which 14,816 people with no history of diabetes at baseline experienced a $21.6 \%$ reduced risk of developing diabetes compared with people treated with amlodipine and a $39.6 \%$ reduced risk compared with people treated with chlor- thalidone during the first 2 years of treatment; (iii) a recent subanalysis of the effect of enalapril on the development of diabetes in participants with left ventricular dysfunction [19]; (iv) the Losartan Intervention for Endpoint Reduction in Hypertension trial, in which individuals with severe hypertension who were treated with the angiotensin-2 receptor blocker losartan had a $25 \%$ lower rate of diabetes diagnosis than those treated with atenolol [20]; (v) the Candesartan in Heart Failure: Assessment of Reduction in Mortality and Morbidity trial, in which individuals with heart failure who were treated with the angiotensin-2 blocker candesartan had a $22 \%$ lower rate of diabetes diagnosis than those treated with placebo [21]; and (vi) epidemiological evidence that ACE inhibitors can increase the risk of hypoglycaemia in people with pharmacologically treated diabetes [22]. Clearly, these findings support, but do not prove, the hypothesis that ACE inhibitors and/or angiotensin receptor blockers prevent diabetes. Indeed, these trials need to be considered in light of the fact that many of them compared ACE inhibitors and/or angiotensin receptor blockers with drugs known to worsen glucose tolerance such as diuretics and/or beta blockers. As such they are unable to distinguish between a protective effect of manipulating the renin-angiotensin system and a harmful effect of the comparator drugs.

Thiazolidinediones may reduce the number of new cases of diabetes. The thiazolidinediones (TZDs) are a class of drugs that reduce fasting and postprandial glucose levels by increasing insulin sensitivity [23]. This beneficial effect on glucose levels has been reported in diabetic individuals as well as in those with IGT, and in short-term studies, the TZD troglitazone converted IGT into NGT in the majority of subjects [24]. Moreover, in a 5-year trial of women with a prior history of gestational diabetes [25], troglitazone reduced the rate of diabetes diagnosis by $55 \%$ (95\% CI: $17-75 ; p=0.009)$. In light of the promising effects of TZDs, the drug troglitazone was initially included as one of the diabetes prevention therapies tested in the Diabetes Prevention Program; it was discontinued after approximately 1 year when an association with liver toxicity was found [26], a problem that has not arisen with rosiglitazone or pioglitazone. Nevertheless, recent data has suggested that the short course of therapy using this drug reduced the number of new cases of diabetes by $75 \%$ and that the effect waned after the drug was stopped [27].

In addition to its effect on glucose, there is evidence to suggest that the TZD rosiglitazone may preserve beta cell mass [28]. Other studies have reported that TZDs reduce atherosclerosis in people with diabetes [29]. As a result, several clinical trials testing whether or not TZDs reduce CV events are currently in progress. 
Table 1. Exclusion criteria

Criteria Definition of criteria

Drug use

Cardiovascular
disease

Other criteria a) Current use of ACE inhibitors and/or TZDs and inability to discontinue these medications

b) Known hypersensitivity to ACE inhibitors

c) Prior use of oral hypoglycaemic medications except during pregnancy

d) Use of systemic glucocorticoids or niacin

a) Ejection fraction known to be $<40 \%$ or congestive heart failure, or existing clinical CV disease (previous myocardial infarction or stroke; angina with either $>50 \%$ stenosis in two or more major coronary arteries, or ST depression of $\geq 2 \mathrm{~mm}$, or a positive nuclear test, previous coronary angioplasty, stent or bypass; previous limb bypass or vessel angioplasty or angiographic evidence of $>50 \%$ stenosis, or intermittent claudication with an ankle/arm pressure of $\leq 0.8$ )

b) Uncontrolled hypertension requiring ACE inhibitors or angiotensin-2 receptor blockers

a) History of diabetes (except gestational diabetes) or on oral hypoglycaemic medication

b) Renal or hepatic disease

(i) renal artery stenosis

(ii) creatinine clearance $<0.6 \mathrm{ml} / \mathrm{s}$ or serum creatinine $\geq 200 \mu \mathrm{mol} / \mathrm{l}$

(iii) clinical proteinuria ( $\geq 1$ proteinuria on dipstick or $\geq 300 \mathrm{mg}$ of albuminuria/day)

(iv) measured alanine transferase $\geq 2.5$ times the upper limit of normal

(v) active liver disease including jaundice, chronic hepatitis, previous liver transplant

c) Major illness with life expectancy of $<5$ years or that may interfere with participation

d) Use of another experimental drug

e) Pregnant or unwilling to use reliable contraception (fertile women will have a pregnancy test prior to randomisation)

f) Major psychiatric disorder

g) Diseases and medications that affect glucose tolerance (e.g. pheochromocytoma, Cushing's syndrome, acromegaly, steroid-dependent asthma, protease inhibitors, antipsychotics)

h) Unwillingness to be randomised or to sign informed consent

i) Known uncontrolled substance abuse

j) Inability to communicate with clinic staff
The DREAM trial. The DREAM (Diabetes Reduction Assessment with Ramipril and Rosiglitazone Medication) trial is a large, international, multi-centre, randomised and double-blind controlled trial designed to determine whether treatment with ramipril and/or rosiglitazone prevents diabetes or reduces the number of new cases of diabetes in 5269 individuals with IGT or IFG. It will also determine whether either of the drugs restores NGT, lowers fasting or post-load glucose levels, reduces $\mathrm{HbA}_{1} \mathrm{c}$ levels, improves insulin secretion, reduces the chance of an aggregate cardiorenal outcome, or (in a subset of participants enrolled in the STARR substudy [the Study of Atherosclerosis with Ramipril and Rosiglitazone]) reduces the progression of carotid atherosclerosis. A parallel epidemiological follow-up study of consenting individuals screened for the DREAM trial (EpiDREAM) will also identify clinical and biochemical determinants of diabetes and related disorders. A description of the study design and the baseline characteristics of the recruited trial participants is provided.

\section{Subjects, materials and methods}

Eligibility. The study protocol and consent forms were fully reviewed and approved by the ethics committees of all of the participating centres, and all participants provided written informed consent for both screening and randomisation. Eligible participants for the trial were those aged 30 or over with IGT or IFG and no diabetes (i.e. a fasting plasma glucose [FPG] $\geq 6.1 \mathrm{mmol} / \mathrm{l}$ and $<7.0 \mathrm{mmol} / \mathrm{l}$, and a 2 -h plasma glucose $<11.1 \mathrm{mmol} / 1$ after a 75 -g OGTT). Exclusion criteria are listed in Table 1 and included evidence of previous ischaemic CVD, heart failure or low ejection fraction, previous intolerance to ACE inhibitors and/or TZDs, and previous diabetes mellitus.

Screening. Individuals at high risk of developing diabetes were sought using a wide variety of strategies that varied by site and country, and that included public advertising and news reports in the media, internet items, referral from physicians, referral from relatives, poster displays, diabetes screening fairs and direct mailing campaigns. Respondents were invited to attend a screening visit after an overnight fast of at least 8 hours. After consenting to be screened, participants (i) had a brief examination which included anthropometric data, (ii) completed a comprehensive questionnaire which collected demographic, clinical, dietary and physical activity data, (iii) had an electrocardiogram, (iv) provided a urine sample and a fasting blood sample, and (v) consumed $75 \mathrm{~g}$ of anhydrous glucose in $300 \mathrm{ml}$ of water. Additional blood samples were drawn after 30 minutes and after 2 hours. An aliquot of the fasting and 2-h blood sample was assayed locally for plasma glucose to determine eligibility for the trial. Participants with IGT or IFG who met the other eligibility requirements and who consented to the trial then entered the run-in phase, and were given placebo ramipril and placebo rosiglitazone to take daily in a single-blind fashion. Eligible individuals returned for a randomisation visit after 14 to 20 days. 


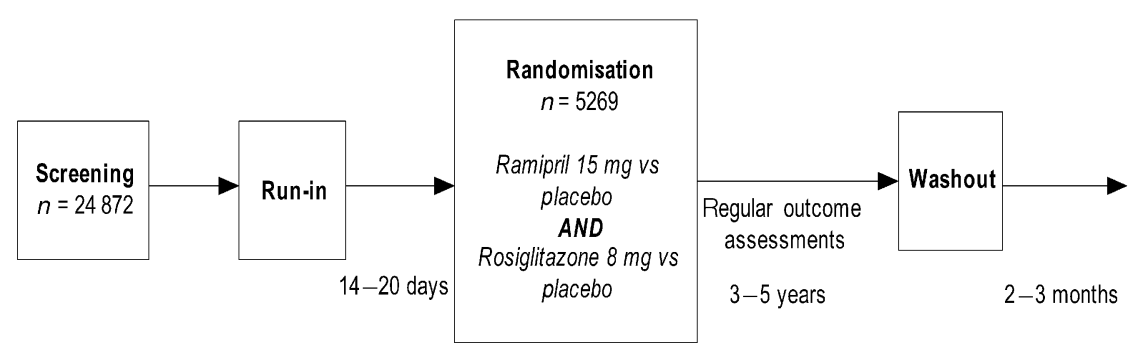

Fig. 1. Design of the DREAM trial

In several countries, participants who did not meet the eligibility requirements, or who declined randomisation, consented to passive follow-up as part of the EpiDREAM study. The follow-up includes brief annual contact and a detailed assessment every 5 years of the impact of the baseline data on the future development of diabetes, IFG, IGT and other metabolic and clinical outcomes.

Randomisation and study intervention. Adherent participants who had not withdrawn consent were then randomised to blinded ramipril (starting at $5 \mathrm{mg} / \mathrm{day}$ ) or placebo, and to blinded rosiglitazone (starting at $4 \mathrm{mg} /$ day) or placebo according to a $2 \times 2$ factorial design (Fig. 1). A subset of consenting individuals in selected sites that were able to measure carotid atherosclerosis ultrasonographically was enrolled in the STARR substudy. Once randomised, every participant will be followed until the scheduled study end, and all outcome events will be recorded even if blinded study medication has been stopped.

Follow-up blood testing for creatinine and potassium will occur at 0.5 months, and follow-up visits will occur at 2 months, 6 months, and then every 6 months thereafter, and all outcomes and events will be recorded until 3 years after the last patient is randomised. At the 2-month visit, the dose of ramipril study drug will be titrated to $10 \mathrm{mg}$ and the dose of rosiglitazone study drug will be titrated to $8 \mathrm{mg}$. At the 1-year visit, the dose of ramipril study drug will be titrated to $15 \mathrm{mg} /$ day.

Participants and their primary care physicians are provided with a list of all available ACE inhibitors, angiotensin- 2 blockers and TZDs, and are advised to avoid these drugs and to inform the research staff if they are prescribed. If diabetes is diagnosed and requires pharmacological therapy, anti-hyperglycaemic agents other than a TZD will be prescribed and rosiglitazone study drug will be continued. If a participant develops a clear indication for an ACE inhibitor, ramipril study drug will be stopped to allow for the prescription of an open-label ACE inhibitor.

Ascertaining the primary outcome. The primary outcome is the development of diabetes, or death from any cause, during the treatment period (i.e. not during the subsequent washout period). Death is included to account for the association between diabetes and mortality and to avoid the problem of competing risk (i.e. diabetes may develop at a different rate in individuals who die than in individuals who do not).

Participants will be screened for diabetes at the 2-year and final visit by a formal 75-g glucose tolerance test with local glucose measurement. At other annual visits, a local fasting plasma glucose and glycated haemoglobin level will be measured, and an OGTT will be scheduled for the next visit in 6 months if the FPG is higher than $5.3 \mathrm{mmol} / \mathrm{l}$ and lower than $7 \mathrm{mmol} / \mathrm{l}$, and the glycated haemoglobin is higher than $93 \%$ of the upper limit of normal for the assay (e.g. 5.6\% if the upper limit is 6\%) [30]. If at any time the FPG or the 2-h plasma glucose satisfies the diagnostic criteria for diabetes, a confirmatory local OGTT will be performed within 3 months. If neither the FPG nor the 2-h plasma glucose in the confirmatory local OGTT satisfies the diagnostic criteria for diabetes, an OGTT will be repeated at the next annual visit and then at each of the annual visits until the end of the study, or until diabetes is diagnosed.

Diabetes mellitus will be diagnosed if: (i) any diagnostic plasma glucose threshold is reached or exceeded on any two consecutive occasions, on two different days, in a 3-month period (i.e. the locally measured FPG is $\geq 7 \mathrm{mmol} / \mathrm{l}$, or the local 2-h plasma glucose is $\geq 11.1 \mathrm{mmol} / \mathrm{l}$ ); or (ii) a diagnosis has been made by a participant's physician, an oral hypoglycaemic agent has been prescribed, and evidence of a confirmatory glucose concentration can be obtained (FPG $\geq 7 \mathrm{mmol} / \mathrm{l}$, or any glucose $\geq 11.1 \mathrm{mmol} / \mathrm{l}$ ).

The drug washout evaluation. Individuals on an active drug and who do not develop diabetes during the trial may simply be responding to a glucose-lowering effect that could disappear as soon as the drug is stopped. Such an effect may occur with metformin [31]. To differentiate between this possibility and a more fundamental effect that reverses or arrests the process of diabetes development, the FPG and the $\mathrm{HbA}_{1} \mathrm{c}$ will be reassessed after a washout period of 2 to 3 months, during which two single-blind placebo drugs will be taken. Therefore, all participants will have an FPG and an $\mathrm{HbA}_{1} \mathrm{c}$ test done at this time. In addition, participants with no diagnosis of diabetes by the end of the active phase will undergo a final OGTT.

Ascertaining secondary outcomes. The key secondary outcome will be a combined cardiorenal outcome defined as either: (i) CV events (myocardial infarction, any stroke, CV death, revascularisation procedures, heart failure, new angina [with objective evidence of ischaemia], or ventricular arrhythmia requiring resuscitation); or (ii) renal events (progression of normoalbuminuria to microalbuminuria or macroalbuminuria, or progression of microalbuminuria to macroalbuminuria [clinical proteinuria], or a $30 \%$ decrease in calculated creatinine clearance). Other secondary outcomes include changes in simple measures of beta cell function, insulin resistance, glucose tolerance, glycaemic indices, albuminuria, ECGs, and reversion to NGT and normal fasting glucose.

The effect of the interventions on the progression of carotid atherosclerosis is being measured in the STARR substudy. Participants of the STARR are having a B-mode carotid ultrasound measurement of the carotid intimal-media thickness at baseline and annually until the study end.

Sample size and statistical analyses. The recruited sample size of 5269 individuals with IGT or IFG (see Results) has an estimated incidence of diabetes or death exceeding $4.5 \%$ per year, and will provide $90 \%$ power to detect a risk reduction attributable to ramipril or rosiglitazone of $22 \%$ or more (assum- 
ing a type 1 error rate of $5 \%$ and $10 \%$ subadditivity between the interventions) during a projected follow-up period of 3 to 4 years. If the rate of diabetes diagnosis is significantly lower than anticipated, the duration of follow-up may be increased to maintain study power. The recruited sample size of 1427 participants in the STARR substudy provides at least $80 \%$ power to detect a difference in the rate of progression of carotid atherosclerosis of 25 to $30 \%$.

The final results will be analysed using an intent-to-treat approach, whereby all participants in their randomly assigned treatment group will be included, regardless of their adherence to the assigned treatment regimen. All analyses of the results for rosiglitazone will be stratified for the effect of ramipril, and vice versa. The primary analysis will be of time to confirmed development of diabetes or death using a Cox proportional hazards model, stratified by the other treatment in the factorial design. For each of these treatments, statistical significance will be claimed if the $p$ value is 0.05 or less. Possible interaction of the two treatments will be assessed by the inclusion of an interaction term in the model.

An independent Trial Monitoring Committee (TMC) is monitoring the study, and reviews the four planned interim analyses using conservative warning rules for efficacy (a reduction in the primary outcome by 4 standard deviations in the first half of the trial or 3 standard deviations in the second half)

Table 2. International recruitment

\begin{tabular}{lcrc}
\hline Region & $\begin{array}{l}\text { Number of } \\
\text { active sites }\end{array}$ & Screened & Randomised \\
\hline North America & 83 & 10,025 & 2149 \\
South America & 32 & 4650 & 1136 \\
Europe & 55 & 5125 & 1104 \\
India & 6 & 4214 & 662 \\
Australia & 15 & 858 & 218 \\
Total & 191 & 24,872 & 5269 \\
\hline
\end{tabular}

a An active site is one in which there are one or more randomised participants and harm (an excess of 3 standard deviations in the first half or 2 standard deviations in the second half). The TMC may recommend an extension in follow-up duration to maintain study power. Alternatively, if the statistical warning rule is triggered twice, and the totality of evidence is consistent with the analyses, the TMC will unblind the principal investigator to discuss early termination. If the results are clear for one intervention but not for the other, the study will continue to evaluate the other intervention.

\section{Results}

Recruitment began on 4 July 2001 and ended on 15 August 2003. During this period a total of 191 clinical sites in 21 countries screened 24,872 individuals and randomised 5269 participants using a variety of recruitment strategies (Table 2). The clinical and glycaemic baseline characteristics of these individuals are noted in Tables 3 and 4 . Of note is that the inclusion criteria were expanded to include individuals with isolated IFG in early 2003, and not all sites recruited this group of individuals. Thus, the proportion of individuals with isolated IFG does not reflect the prevalence of that abnormality throughout the screening period. Table 4 also shows the numbers of individuals who would be classified as having isolated IFG and isolated IGT based on the recently proposed lower threshold for the category of IFG (i.e. an FPG of $\geq 5.6 \mathrm{mmol} / \mathrm{l}$ ) that was chosen after epidemiological analyses. The data suggest that this threshold predicted a risk of future diabetes similar to that predicted by the 2-h IGT threshold [32].

Details regarding the 1427 participants of the STARR substudy, and regarding the screened participants who consented to be followed in EpiDREAM, will be reported separately.

Table 3. Baseline clinical characteristics of recruited and screened participants

\begin{tabular}{lcc}
\hline Characteristic & Screened & Randomised \\
\hline Total screened and randomised & 24,872 & 5269 \\
Age (years) & $52.5(11.3)$ & $54.7(10.9)$ \\
Females & $14,865(60.0)$ & $3084(58.5)$ \\
History of abnormal glucose & $4046(16.3)$ & $1259(24.0)$ \\
Women with prior gestational diabetes & $1284(8.7)$ & $286(9.3)$ \\
History of hypertension & $8527(34.4)$ & $2285(43.5)$ \\
History of hyperlipidaemia & $7298(29.5)$ & $1861(35.5)$ \\
Systolic blood pressure (mm Hg) & $132.0(19.4)$ & $136(18.6)$ \\
Diastolic blood pressure (mm Hg) & $81.5(12.9)$ & $83.4(11.3)$ \\
Weight (kg) & $81.7(19.4)$ & $84.8(19.2)$ \\
BMI (kg/m $\left.{ }^{2}\right)$ & $29.5(5.4)$ & $30.5(5.1)$ \\
WHR men & $0.95(0.1)$ & $0.96(0.1)$ \\
WHR women & $0.85(0.1)$ & $0.87(0.1)$ \\
Waist circumference men (cm) & $85.6(28.1)$ & $87.0(27.5)$ \\
Waist circumference women $(\mathrm{cm})$ & $78.3(28.3)$ & $82.7(30.1)$ \\
Ankle/brachial index & $1.2(0.2)$ & $1.2(0.2)$
\end{tabular}

Data are expressed as means (SD) or $n(\%)$ 
Table 4. Baseline glycaemic characteristics of recruited and screened participants

\begin{tabular}{lcr}
\hline & Screened & Randomised \\
\hline Total screened and randomised & 24,872 & 5269 \\
Total with IGT & $6036(24.3)$ & $4527(85.9)$ \\
Total with IFG & $3699(14.9)$ & $2234(42.4)$ \\
Isolated IGT & $4085(16.4)$ & $3032(57.5)^{\mathrm{a}}$ \\
Isolated IFG & $1748(7.0)$ & $739(14.0)^{\mathrm{a}}$ \\
Both IGT and IFG & $1951(7.8)$ & $1495(28.4)^{\mathrm{a}}$ \\
Possible diabetes & $3630(14.6)$ & $3(0.06)^{\mathrm{a}}$ \\
Mean FPG & $5.7(1.7)$ & $5.8(0.7)$ \\
Mean 2-h plasma glucose & $7.6(3.2)$ & $8.7(1.4)$ \\
Total with IFG (with new IFG definition) & $7957(32.0)$ & $3431(65.1)$ \\
Isolated IGT (with new IFG definition) & $2487(10.0)$ & $1835(34.8)$ \\
Isolated IFG (with new IFG definition) & $4408(17.7)$ & $739(14.0)$ \\
Both IGT and IFG (with new IFG definition) & $3549(14.3)$ & $2692(51.1)$ \\
\hline
\end{tabular}

a Three individuals had a baseline FPG that suggested possible diabetes, and were randomised when they should have been excluded. Their 2 -h results during the OGTT were all in the IGT range; their actual fasting and 2-h plasma glucose values (mmol/l) were (respectively): (i) 7.0 and 10.9, (ii) 7.0 and 10.1, and (iii) 7.0 and 9.1. Data are expressed as $n(\%)$. IFG by old definition, an FPG of $\geq 6.1 \mathrm{mmol} / \mathrm{l}$; IFG by new definition, an FPG of $\geq 5.6 \mathrm{mmol} / \mathrm{l}$; isolated IFG, IFG and no IGT; isolated IGT, IGT and no IFG

\section{Discussion}

The DREAM trial of 5269 multi-ethnic individuals at high risk of diabetes will determine whether two promising therapeutic strategies, ramipril and rosiglitazone, prevent or delay the development of diabetes. It is a large, simple trial that will: (i) detect or exclude moderate benefits of therapy; (ii) determine the durability of any benefit in a broad range of high-risk participants with IGT and/or IFG throughout the world; and (iii) assess the impact of these interventions on the progression of carotid atherosclerosis (in the STARR substudy). It also includes mechanistic studies to assess insulin resistance and beta cell function, and provides opportunities to analyse stored blood samples in order to further our knowledge regarding the development of diabetes mellitus. Moreover, the EpiDREAM study of the patients screened during the DREAM trial will identify novel demographic, clinical, dietary, activity-related, biochemical and physiological determinants of diabetes, obesity and related metabolic disorders.

The promise of any therapeutic strategy that prevents or delays diabetes lies in the assumption that preventing diabetes will also prevent the cardiovascular, renal, retinal, neurological and other consequences of the disease. Such an assumption remains unproven for the diabetes prevention studies that have been published to date, but is supported in the case of CVD by: (i) the long-term benefits of metformin when given to people with newly diagnosed diabetes [33]; and (ii) a recent analysis of the small number of CVD events reported in a trial of acarbose for the prevention of diabetes [34]. Ramipril is already known to reduce the risk of CVD and renal disease in high-risk diabetic individuals and in non-diabetic individuals with vascular disease [8]. If it also reduces the risk of the development of diabetes in individuals with no evidence of vascular disease or diabetes, the potential public health benefit of utilising this drug will be clearly magnified. Similarly, the beneficial effect of rosiglitazone on insulin resistance and other cardiovascular risk factors, and evidence that other TZDs reduce atherosclerosis [29, 35], suggests that rosiglitazone will also attenuate the complications of diabetes. This possibility is being tested within the DREAM trial as well as in other clinical trials with rosiglitazone.

Finally, the implications of this trial extend beyond the prevention of diabetes mellitus. The interventions are being tested in individuals with IFG and IGT, metabolic states that are themselves strong risk factors for CVD. Thus, in addition to determining whether they prevent diabetes, the DREAM trial will determine whether either drug alone (or both together) can repair an abnormal gluco-metabolic state and are thus an effective treatment for dysglycaemia. Moreover, a positive result for either or both drugs will suggest that the links between the renin-angiotensin system, glucose homeostasis [36] and CV disease are clinically important, and will highlight the relevance of elevated glucose levels as potentially responsive risk factors for $\mathrm{CV}$ disease.

Acknowledgements. The DREAM trial is funded by the Canadian Institutes of Health Research (MCT41548) as well as by Aventis Pharma, GlaxoSmithKline, King Pharmaceuticals and Wyeth Ayerst. 
Writing Committee for this paper: H. C. Gerstein, S. Yusuf, R. Holman, J. Bosch, J. Pogue

Steering Committee: H. Gerstein (Co-chair and Co-PI), S. Yusuf (Co-chair and Co-PI), R. Holman (European Cochair), G. Dagenais, J. Probstfield, J. Bosch (Project Director), S. Anand, A. Avezum, A. Budaj, S. Capes, J. L. Chiasson, V. Christian, I. Conget, M. Davies, R. Diaz, N. Dinccag, A. Escalante, G. Fodor, M. Freed, M. Hanefeld, A. Hartung, A. Himmelmann, M. Keltai, M. Laakso, F. Lanas, E. Lonn, M. McQueen, V. Mohan, W. Schulz, I. Schmid, J. Shaw, K. Teo, P. Zimmet, B. Zinman

\section{Site Investigators by country:}

Argentina: R. Diaz, R. A. Ahuad Guerrero, J. P. Albisu, M. A. Amado Eleas, V. Arregui, H. A. Avaca, H. P. Baglivo, F. H. Bello, J. Bono, A. Caccavo, G. D. Caime, L. R. Cartasegna, J. H. Casabe, R. Castellanos, L. A. Castro, M. Centeno, L. N. Citta, N. Citta, C. A. Cuneo, L. de Loredo, R. H. Denaro, J. F. de Rosa, E. M. Esperatti, H. Farras, A. Fernandez, G. M. Ferrari, A. J. Gambarte, M. Garrido, A. Hershon, M. I. Klyver, C. T. Laugle, A. G. Liberman, L. L. Lobo Marquez, R. R. Lopez, J. A. Lowenstein, C. Luquez, I. MacKinnon, M. C. Maffia, C. R. Majul, E. M. Marzetti, O. Manuale, G. Marcucci, M. S. Martos, R. Memoli, O. Montana, A. Orlandini, J. A. Piasentin, G. A. Pignolo, D. Piskorz, M. L. Plastino, J. C. Pomposiello, C. Ramos, F. H. Ramos, H. Ramos, A. Risolo, S. S. Saavedra, L. Sago, R. Sanchez, P. O. Schygeil, O. Sotomayor, M. Vico, M. L. Vico, A. J. D. Vizcaya Castro, C. J. Zaidman

Australia: J. Shaw, P. Zimmet, C. Allen, P. Buchanan, D. Calvert, M. Cochran, S. Colagiuri, P. Colman, M. Correcha, M. d'Emden, J. Freeborn, H. Friebel, G. Fulcher, C. Glatthaar, J. Graham, P. Hackney, V. Heazlewood, B. Higgins, J. Karrasch, A. Marangou, A. Matthiesson, K. Michaelis, R. Moses, V. Naidu, A. Nankervis, R. O'Brien, H. Parry, P. Patrikios, N. Petrovsky, J. Proietto, A. Roberts, C. Rodgers, G. Ross, R. Simpson, R. Slobodniuk, B. Stuckey, D. Topliss, J. Twomey, J. Walsh, J. Warner, S. Wigg, S. Wu, D. Yue, R. Yuen

Bermuda: S. Marshall

Brazil: A. Avezum, M. C. Bertolami, J. Borges, D. Branco de Araujo, A. F. Da Silva, M. do Socorro, A. A. Faludi, S. Grespan, J. L. Gross, A. Halpern, A. H. Hirota, C. Leiteo, O. Monte, J. E. Nunes Salles, O. Oliveira, A. Rabelo Jr, L. M. Rabelo, L. A. Turatti, H. Zatz

Canada: G. Dagenais, C. Abbot, A. Abu Bakare, M. Ali, R. C. Allison, S. Anand, J. P. Beauchef, A. Belanger, B. Bell, G. Bondy, P. Bonin, R. Bouchard, P. Bragaglia, S. Brault, R. Brossoit, B. Caloyannis, S. Capes, J. Cha, L. Chalklin, P. Champion, S. Chan, Y. Chan, R. Cheung, J. L. Chiasson, M. Chilvers, J. R. Conway, T. R. Czolpinski, R. Denton, D. Donat, M. Drapeau, R. Dumas, S. Duncan, H. Duong, D. Eddy, D. Fay, D. Feig, L. Fischer, F. Fraser, L. Frenette, J. Frohlich, M. L. Fyfe, J. A. Gagnon, G. Girard, G. Gosselin, D. Grunbaum, M. Gupta, J. P. Halle, A. Hanley, P. Hardin, S. Harris, G. Hoag, B. Horner, R. Houlden, R. Jacques, O. Jenkins, G. Koop, J. Kramer, A. Kuchtaruk, S. Kwan, C. Lai, A. Lam, D. Lau, T. Leary, H. Lee, H. Lochnan, S. M. Ludwig, J. C. MacFadyen, S. S. Mann, J. Mckay, A. McLean, M. Mills, C. Mindru, D. Monier, L. J. Murphy, D. L. O'Keefe, G. Ouellet, M. Parmar, P. Pelletier, R. J. Petrella, R. Phillips, M. Pilon, R. Rabasa Lhoret, A. R. Rajakumar, G. Rajakumar, G. Rideout, Y. Robitaille, R. Rowe, D. Saunier, D. Savard, R. Sayeed, G. Schacter, F. Sestier, J. Shaban, D. Shu, J. Silverberg, R. J. Smith, R. Starra, D. Steinson, D. Stewart, C. St. Pierre, B. Sussex, S. Swaran, G. Thomson, N. U. Troung, E. Tsui, F. Turcotte, J. van Buuren, R. Verdonk, D. Wallik, P. Whitsitt, C. Williams, R. Wilson, L. Winkler, W. Wong, V. C. Woo, P. Wozniak, J. F. Yale, B. Zinman, T. Zmijowskyj
Chile: F. Lanas, M. X. Atkinson Altamirano, F. A. Bello Murua, G. Larenas, V. Raddatz Kiefer

Finland: M. Laakso, J. Eriksson, L. Hiltunen, S. KeinänenKiukaanniemi, M. Laakso, S. Ruotsalainen, V. Salaspuro, K. Sivenius, J. Strand, T. Valle

Germany: M. Hanefeld, U. Anderson, G. Bennoehr, P. Budziarek, M. Dreyer, S. Engeli, R. Hampel, M. Hauskla, E. Henkel, J. Jordan, A. Kohn, C. B. Kresse, H. Mehling, E. Mileva, P. Ott, M. Pein, F. Pistrosch, G. Scholz, U. Stier, T. Temelkova-Kurktschiev, K. Wilhelm

Hungary: M. Keltai, Z. Birkus, T. Boros, K. Hati, P. Kempler, S. Kornel, F. Nagy, C. Nemeth, F. Poor, P. Pusztai, K. F. Sandor, A. Somogyi, G. Szekely, J. Takacs, A. Toth, E. Varga, P. Voros, L. Zoltan

India: V. Mohan, S. Aravind, S. R. Aravind, M. Dharmalingam, K. M. P. Kumar, P. Pais, P. V. Rao, K. Shailaja, C. S. Yajnik

Latvia: E. Gailiss, S. Gara, A. Gozite, S. Hansone, I. Konrade, I. Kreislere, L. Liepa, D. Lisova, M. A. Ozolina, V. Pirags, L. Putane, J. Raibarts, I. Rasa, R. Ritenberga, J. Romanova, N. Rozkova, E. Rudzite, A. Staka, V. Svarcberga, A. Trenins, A. Valtere, I. Veze, J. Zemmers

Mexico: A. Escalante, S. Arellano Montano, C. G. Calvo Vargas, E. G. Cardona Munoz, R. Castaneda, I. J. Chavira Lopez, A. Correa, L. Cortinas Lopes, M. de Los Angeles Rios Arellano, C. Dominguez, M. Escalante, D. Gonzalez Barcena, C. Granados Gomez, H. Hernandez, S. Hernandez Jiminez, A. Herrera, J. J. Illescas Diaz, L. Mancillas Adame, R. Mazariegos, L. Mejia Solis, C. Mendoza, L. Mendoza Cano, T. Munoz, A. Olmos, M. H. Orozco Gutierrez, S. Pascoe, M. L. Perez, P. Ramirez, C. Ramos, A. Reza Albarran, I. Rubio Benitez, M. Sanchez, M. J. Sil Acosta, A. Solis, M. Vidrio

Netherlands: E. A. M. Bardelmeijer, S. J. Eelkman Rooda, J. Huizer, J. Jonker, P. C. Oldenberg Ligtenberg, D. Ramautarsing, V. van de Walle, W. W. van Kempen

Norway: E. Bjornstad McFadden, B. J. Bryne, A. B. H. Faehn, K. Furuseth, J. Halse, T. Henriksen, O. G. Knudsrod, S. Vaaler

Poland: A. Budaj, A. Baranowska, M. Baranska, J. Blaszak, M. Bronisz, P. Burduk, L. Ceremuzynski, E. Czempik, M. Gmystraiewicz, A. Grochola, O. Grzegorz, P. Ignaczak, K. Janik, G. Kania, T. Kawka Urbanek, D. Kopcik, M. Kordys, J. Majer, P. Miekus, J. Mormul, A. Mrowczynska, D. Nowak, P. Nowakowski, M. Ogorek, L. V. Oleskowaska, L. Paliszewska, B. Przywoska Para, S. Pszonak, M. Rozwodowska, M. Rucinski, M. Rzyman, M. Sikora Frac, J. Stecka Wierzbicka, M. Swiatkowski, R. Swierczynski, M. Szpajer, M. Ukleja Adamowicz, A. Urbaniak, D. Winek, P. Wojewoda, J. Zadrosny, J. Zak, B. Zalska

Slovakia: G. Fodor, M. Bilicky, A. Dukat, J. Kralova, V. Krpciar, J. Lietava, E. Lipsic, A. Vachulova, I. Vacula

Spain: I. Conget, E. Aguilera Hurtado, C. Angels, J. I. Bernardino, C. Campo Sien, R. Cararro Casieri, L. de Teresa Pareno, L. T. Diez, R. Gabriel, A. Garcia Herola, A. Gomez Pan, L. Guerrero Llamas, G. Hermosa, J. G. Puig, C. Roldan, L. M. Ruilope Urioste, J. Segura, I. Serrano

Sweden: A. Himmelmann, H. E. M. Anders, S. L. Andren, A. L. Erikkson, L. U. Jungersten, H. J. Nielsen, L. Ny, B. G. Polhem, S. Skrtic, S. Svensson, S. Wallerstedt

Turkey: N. Dinccag, F. Falman, S. Salman, I. Satman

UK: M. Davies, O. Ali, J. Barron, L. J. Borthwick, N. Capps, S. Chatterjee, S. S. Dale, P. Davies, C. Fox, J. Furnace, A. George, A. Harrower, M. Hollway, K. MacLeod, M. J. MacLeod, D. M. Mathews, K. Mills, A. Millward, G. Nayani, A. Neil, M. Page, T. Reynolds, S. Ross, R. Sriraman, J. Tringham

USA: J. Probstfield, E. Albright, S. Anderson, A. A. S. Arghi, G. Bakris, A. Bastien, D. S. Bell, R. Bergenstal, J. T. 
Bigger, D. F. Brautigam, R. Burgos Calderon, W. Cushman, J. de Lemos, D. S. Donovan, W. Elliot, A. Farag, J. Flack, S. D. Garay, J. Garcia, D. Garcia de la Rosa, A. S. Getaneh, H. Ginsberg, R. S. Goland, R. Goldberg, R. Grimm, H. Guber, M. Hagen, K. Hall, A. H. Hamrahian, B. Hoogwerf, S. Houghton, M. Izhar, L. Joseph, S. E. Kempainen, D. Kendall, R. Kowal, P. Linz, K. Margolis, S. McFarlane, J. McGill, D. McGuire, G. Medina Caban, A. E. Mehta, L. Merkle, B. R. Meyer, L. Montalvo Burke, P. Mora, G. S. Neri, C. Octaviani, R. Ostlund, F. Ovalle, P. Pepper, M. Riddle, J. J. Shim, E. Siraj, S. S. Solomon, J. Spencer, E. Stephens, W. Vega Ocasio, K. Wyne, R. S. Zimmerman

\section{DREAM Project Offices:}

Global: J. Bosch, C. Choppick, S. Dawkins, D. Desai, H. C. Gerstein, K. A. Kimura, L. MacRae, R. Masney, C. Nsiah, C. Nurnberg, J. Pogue, G. Roubos, P. Sheridan, K. Simek, S. Yusuf

Argentina: A. Pascual, C. Rovito

Australia: M. Palmer

Brazil: P. Smith

Chile: A. Montecinos

Europe: A. Feroleto, R. Holman, J. Keenan, J. Starrett

India: P. Keertikar, V. Kulkarni, V. Kumar HG, S. Vora

Mexico: J. Morales

USA: E. M. Kurashige, J. Probstfield, K. Worrell

\section{DREAM Centre Study Coordinators:}

Argentina: O. R. Arrieta, A. O. Baiporria Jayat, F. A. Cacace, A. M. Cacurri, A. M. Carrique, M. Cerdan, F. L. Cersosimo, P. Y. Crunger, M. Focaccia, A. J. Gabito, I. Garrido, C. M. Lucero, H. L. Luciardi, E. Luduena Clos, M. M. Luna, A. M. Orozco, S. G. Saladaar, G. A. Suarez, R. D. Vieira Mino, M. C. Villavona

Australia: B. Brooks, J. Candido, M. Dwyer, J. Gein,

A. Grogan, A. Hodge, M. Lawton, C. Murphy, T. Nugent,

K. Robinson, E. Tapp

Bermuda: D. Jones

Brazil: Y. Nakamura

Canada: C. Allison, D. Auger, K. Barban, A. Barnie, L. D. Berard, J. Bradley, M. A. Brittain, S. Brown, P. Carmichael, I. Chausse, M. A. Clearwaters, C. Colborne, L. Coruana, S. Dallaire, D. Dalpe, M. David, A. D. Davis, J. de Jesus, S. Erickson Nesmith, M. Ferguson, L. Fotherby, G. Fox, K. Fraser, S. Gauthier, K. Gibbs, P. Gilmour, K. Grant, P. Harton, M. T. Hughes, D. Johnston, J. Krider, C. Labrecque, C. LaVallee, T. LaVallee, W. Leong, K. Lessard, J. MacKay, D. MacNair, D. L. Mallette, M. Marin, J. Marruci, M. Marsh, G. McCarthy, T. McGrath, S. McLean, L. Michaud, D. Mitchell, S. Newman, J. Otis, S. Petrella, R. A. Poirier, D. Poisson, S. Prieur, C. Proteau, C. Robert, Z. Sayeed, A. Scott, T. Seguin, B. Stearn, C. Stephenson, F. Stone, S. Talbot, D. Taylor, D. Tippe, A. M.

Tkachuk, A. Toupin Halle, M. Tsigoulis, L. Zaychakowsky

Germany: G. Flehmig

Hungary: Z. Hermanyi

India: J. George, A. Joglekar, K. Karkuzhali, P. D. Manduva,

S. Prakash, P. Subramanian, Usha

Mexico: V. Padilla

Netherlands: L. van Es, L. van Setten van der Meer

Norway: B. Enderle, K. H. Murud

Slovakia: K. Adamo, M. Gajdosova

Spain: L. Fernandez Lopez, R. Gomis, P. Lopez, E. Sanchez Sweden: G. Lindh, C. Tukukino

Turkey: Y. Tutuncu

UK: B. Barrow, J. Beaverstock, M. Bruce, S. Dickson, E. Forrester, K. Gallagher, K. Hall, J. Maiden, M. McIntosh, K. Neeves, A. Shore, S. J. Tattersfield, L. Tonks
USA: R. Alexander, E. Anteola, S. Baker, E. Basta, J. Becker, D. Cacia, C. Carlson, C. Charles, M. Cipolle, L. Coley, L. DeVivo, C. Flanders, P. I. Fuste Fontanez, S. Griffin, L. Griffith, W. A. James, J. Kalisch, M. P. Kringas, C. R. Lopez Jiminez, A. Mazin, P. McDaniel, A. Monk, J. Ojito, J. Ramirez, M. Vetrano, S. Walsh

External Trial Monitoring Committee (Data Safety and Management Board): D. L. Sackett, D. Altman, P. Bennett, C. M. Clark, R. Hamman, L. Ryden

\section{References}

1. Harris MI, Flegal KM, Cowie CC et al. (1998) Prevalence of diabetes, impaired fasting glucose and impaired glucose tolerance in U.S. adults. The third National Health and Nutrition Examination Survey, 1988-1994. Diabetes Care 21:518-524

2. Hogan P, Dall T, Nikolov, P, American Diabetes Association (2003) Economic costs of diabetes in the U.S. in 2002. Diabetes Care 26:917-932

3. Gerstein HC, Capes SE (2002) Dysglycemia: a key cardiovascular risk factor. Semin Vasc Med 2:165-174

4. DECODE Study Group (2003) Is the current definition for diabetes relevant to mortality risk from all causes and cardiovascular and noncardiovascular diseases? Diabetes Care 26:688-696

5. Knowler WC, Barrett-Connor E, Fowler SE et al. (2002) Reduction in the incidence of type 2 diabetes with lifestyle intervention or metformin. N Engl J Med 346:393-403

6. Tuomilehto J, Lindstrom J, Eriksson JG et al. (2001) Prevention of type 2 diabetes mellitus by changes in lifestyle among subjects with impaired glucose tolerance. N Engl J Med 344:1343-1350

7. Chiasson JL, Josse RG, Gomis R, Hanefeld M, Karasik A, Laakso M (2002) Acarbose for prevention of type 2 diabetes mellitus: the STOP-NIDDM randomised trial. Lancet 359:2072-2077

8. HOPE Study Investigators (2002) Effects of an angiotensin-converting-enzyme inhibitor, ramipril, on cardiovascular events in high-risk patients. N Engl J Med 342:145-153

9. The SOLVD Investigators (1992) Effect of enalapril on mortality and the development of heart failure in asymptomatic patients with reduced left ventricular ejection fractions. N Engl J Med 327:685-691

10. The SOLVD Investigators (1991) Effect of enalapril on survival in patients with reduced left ventricular ejection fractions and congestive heart failure. $N$ Engl J Med 325:293-302

11. Pfeffer MA, Braunwald E, Moye LA et al. (1992) Effect of captopril on mortality and morbidity in patients with left ventricular dysfunction after myocardial infarction. N Engl J Med 327:669-677

12. Zuanetti G, Latini R, Maggioni AP, Franzosi M, Santoro L, Tognoni G (1997) Effect of the ACE inhibitor lisinopril on mortality in diabetic patients with acute myocardial infarction: data from the GISSI-3 study. Circulation 96:4239-4245

13. Yusuf S, Lonn E, Bosch J, Gerstein H (1999) Summary of randomized trials of angiotensin converting enzyme inhibitors. Clin Exp Hypertens 21:835-845

14. Heart Outcome Prevention Evaluation (HOPE) Study Investigators (2000) Effects of ramipril on cardiovascular and microvascular outcomes in people with diabetes mellitus: results of the HOPE study and MICRO HOPE substudy. Lancet 255:253-259 
15. Yusuf S, Gerstein H, Hoogwerf B et al. (2001) Ramipril and the development of diabetes. JAMA 286:1882-1885

16. Lonn EM, Weitz J, Dzavik V, Gerstein H, Yusuf S (2000) Metabolic and hematologic effects of ramipril in the HOPE trial. Circulation 102 [Suppl 2]:408

17. Hansson L, Lindholm LH, Niskanen L et al. (1999) Effect of angiotensin-converting-enzyme inhibition compared with conventional therapy on cardiovascular morbidity and mortality in hypertension: the Captopril Prevention Project (CAPPP) randomised trial. Lancet 353:611-616

18. ALLHAT Collaborative Research Group (2002) Major outcomes in high-risk hypertensive patients randomized to angiotensin-converting enzyme inhibitor or calcium channel blocker vs diuretic: The Antihypertensive and Lipid-Lowering Treatment to Prevent Heart Attack Trial (ALLHAT). JAMA 288:2981-2997

19. Vermes E, Ducharme A, Bourassa MG, Lessard M, White M, Tardif JC (2003) Enalapril reduces the incidence of diabetes in patients with chronic heart failure: insight from the Studies Of Left Ventricular Dysfunction (SOLVD). Circulation 107:1291-1296

20. Dahlof B, Devereux RB, Kjeldsen SE et al. (2002) Cardiovascular morbidity and mortality in the Losartan Intervention For Endpoint reduction in hypertension study (LIFE): a randomised trial against atenolol. Lancet 359:995-1003

21. Pfeffer MA, Swedberg K, Granger CB et al. (2003) Effects of candesartan on mortality and morbidity in patients with chronic heart failure: the CHARM-Overall programme. Lancet 362:759-766

22. Morris AD, Boyle DI, McMahon AD et al. (1997) ACE inhibitor use is associated with hospitalization for severe hypoglycemia in patients with diabetes. DARTS/MEMO Collaboration. Diabetes Audit and Research in Tayside, Scotland. Medicines Monitoring Unit. Diabetes Care 20:1363-1367

23. Hauner H (2002) The mode of action of thiazolidinediones. Diabetes Metab Res Rev 18 [Suppl 2]:S10-S15

24. Antonucci T, Whitcomb R, McLain R, Lockwood D, Norris RM (1997) Impaired glucose tolerance is normalized by treatment with the thiazolidinedione troglitazone. Diabetes Care 20:188-193

25. Buchanan TA, Xiang AH, Peters RK et al. (2002) Preservation of pancreatic beta-cell function and prevention of type 2 diabetes by pharmacological treatment of insulin resistance in high-risk Hispanic women. Diabetes 51:27962803

26. Nijpels G, Popp-Snijders C, Kostense PJ, Bouter LM, Heine RJ (1996) Fasting proinsulin and 2-h post-load glucose levels predict the conversion to NIDDM in subjects with impaired glucose tolerance: the Hoorn Study. Diabetologia 39:113-118

27. The Diabetes Prevention Program Research Group (2003) Prevention of type 2 diabetes with troglitazone in the Diabetes Prevention Program. Diabetes 52 [Suppl 1]: A58

28. Finegood DT, McArthur MD, Kojwang D et al. (2001) Beta-cell mass dynamics in Zucker diabetic fatty rats. Rosiglitazone prevents the rise in net cell death. Diabetes 50:1021-1029

29. Parulkar AA, Pendergrass ML, Granda-Ayala R, Lee TR, Fonseca VA (2001) Nonhypoglycemic effects of thiazolidinediones. Ann Intern Med 134:61-71

30. Anand SS, Razak F, Vuksan V et al. (2003) Diagnostic strategies to detect glucose intolerance in a multiethnic population. Diabetes Care 26:290-296

31. Diabetes Prevention Program Research Group (2003) Effects of withdrawal from metformin on the development of diabetes in the diabetes prevention program. Diabetes Care 26:977-980

32. Genuth S, Alberti KG, Bennett P et al. (2003) Follow-up report on the diagnosis of diabetes mellitus. Diabetes Care 26:3160-3167

33. UK Prospective Diabetes Study (UKPDS) Group (1998) Effect of intensive blood glucose control with metformin on complications in overweight patients with type 2 diabetes (UKPDS 34). Lancet 352:854-865

34. Chiasson JL, Josse RG, Gomis R, Hanefeld M, Karasik A, Laakso M (2003) Acarbose treatment and the risk of cardiovascular disease and hypertension in patients with impaired glucose tolerance: the STOP-NIDDM trial. JAMA 290:486-494

35. Minamikawa J, Tanaka S, Yamauchi M, Inoue D, Koshiyama H (1998) Potent inhibitory effect of troglitazone on carotid arterial wall thickness in type 2 diabetes. J Clin Endocrinol Metab 83:1818-1820

36. Sharma AM, Janke J, Gorzelniak K, Engeli S, Luft FC (2002) Angiotensin blockade prevents type 2 diabetes by formation of fat cells. Hypertension 40:609-611 